\title{
Detecting Evidence of Climate Change in the Forests of the Eastern United States
}

\section{Introduction}

Changes in land use or disturbances such as defoliation by insects, disease, or fire all affect the composition and amount of tree canopy in a forest. These changes are easy to detect. Noticing and understanding the complex ways that global or regional-scale climate change combines with these disturbances to affect forest growth patterns and succession is difficult. This is particularly true for regions where changes in climate are not the most extreme, such as the mid-latitude forests of the Eastern United States. If land and water resources are to be managed responsibly, it is important to know how well the impacts of climate change on these forests can be measured in order to provide the best information possible to respond to any future changes. The goal of this study is to test whether climate-induced changes in forests in the Eastern United States can be detected and characterized using satellite imagery.

\section{A Focus on Landscape Phenology}

Phenology is the study of the influence of climate change on the timing of biological events, such as annual plant flowering and seasonal bird migration. These events are partially driven by changes in temperature and precipitation; therefore, phenology studies how these events may reflect changes in climate. To study climate-change relations over broad areas (at landscape scale), the timing and amount of annual tree leaf emergence, maximum foliage, and leaf fall for forested areas are of interest.

\section{Study Area}

The forests of the Shenandoah National Park in the Blue Ridge province of Virginia (fig. 1) have been protected from major land-use change for many decades. In addition, the National Park Service (NPS) has recorded the dates and often the location of disturbances such as fires and insect infestations. These

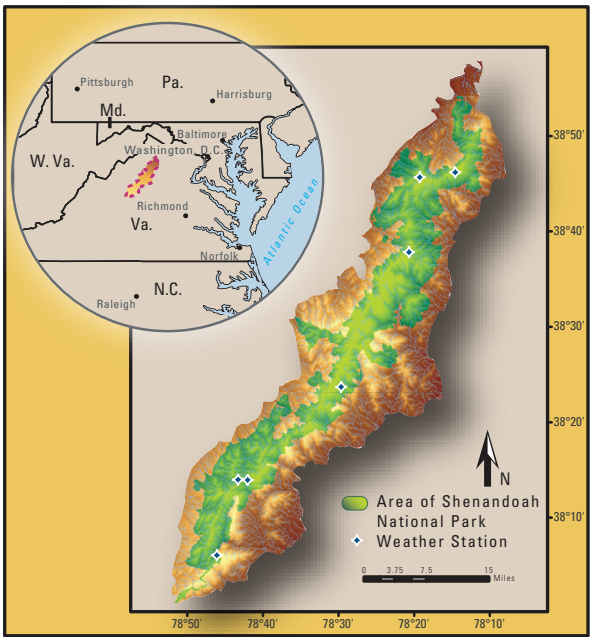

Figure 1. The Shenandoah National Park includes part of the Appalachian Trail along the Blue Ridge of the Eastern United States. factors make the Shenandoah National Park an excellent "laboratory" in which to conduct an experiment.

\section{Approach}

The relation between seasonal forest change and weather is being tracked and analyzed by comparing precise field observations to regional patterns shown in long-term satellite imagery. In consultation with NPS authorities, meteorological stations (fig. 2) have been placed in the park at locations that were selected after considering forest-cover type, the slope of the ground, the direction in which the ground is facing (aspect), and whether there is adequate distance from a trail or historic feature. Most of these stations must be visited periodically for maintenance or to download data; however, two stations provide continuous data retrieval through

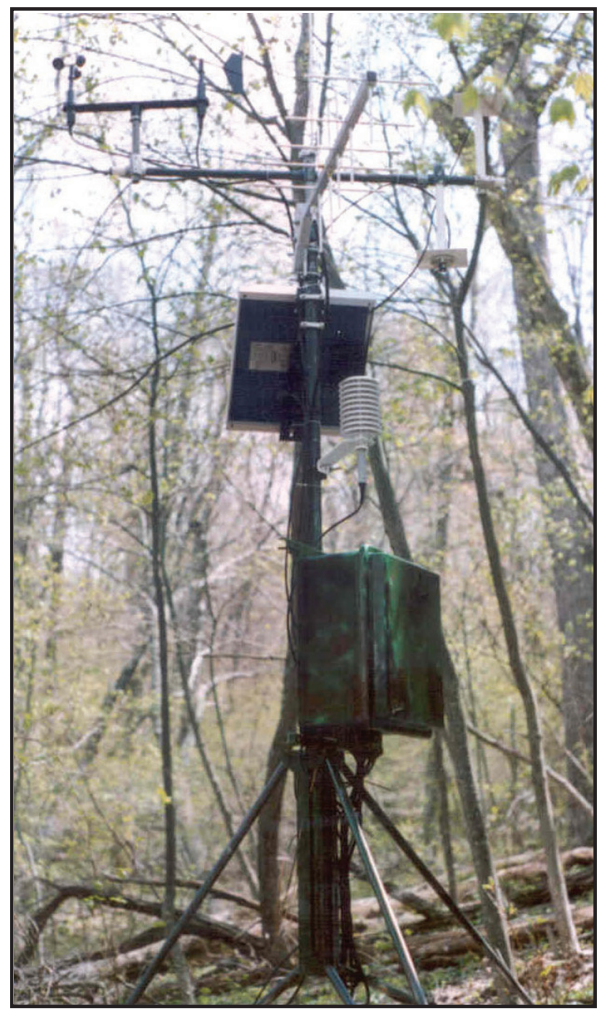

Figure 2. As part of the ground-data collection effort, six weather stations are deployed in the Shenandoah National Park to provide weather data from a sampling of different forest and terrain types.

automated communications with weather satellites; their data are available in real time via the Web at http://erg.usgs.gov. Canopy conditions are recorded periodically using onsite photography (fig. 3) or other handheld instruments. Field observations, which began in 2006, are helping us understand how short-term weather events affect vegetation and how satellite measurements over small areas help us understand the phenology of a local area.

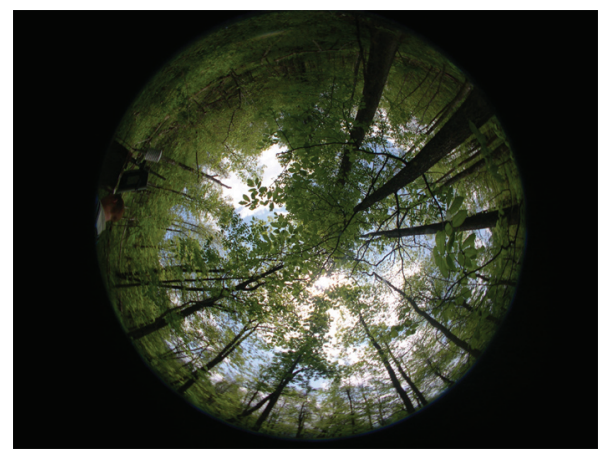

Figure 3. Periodic photographs taken from beneath the canopy using a skyward-facing fish-eye lens can be used to measure when leaves come out and how much tree cover exists at specific locations.

Ground-data collection is full of challenges (fig. 4) and can be both difficult and expensive to continue over a long period of time. Time-sequenced satellite imagery provides an opportunity to observe phenological changes over large areas. Because the changes might be very subtle, frequent recording of satellite images over very long periods of time will be required for the analysis of landscape phenology.

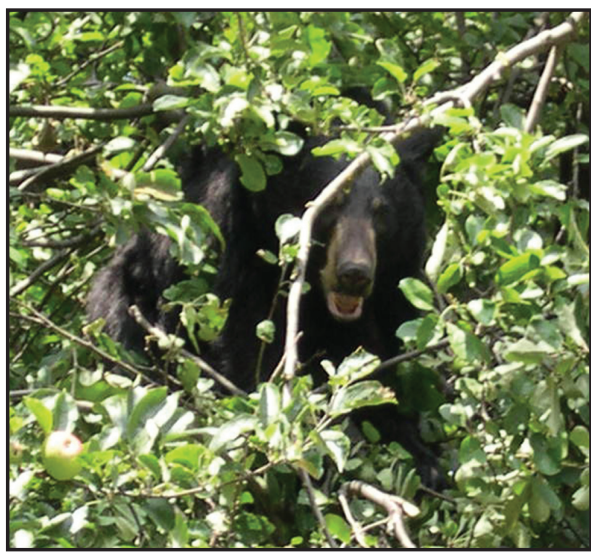

Figure 4. Maintaining weather stations in the park is difficult for a number of reasons. For example, black bears seem to consider them opportunities for play and exercise.

To date, a database of government-produced, moderate-resolution imagery has been assembled for the Shenandoah National Park and surrounding areas. The Landsat and the Advanced Very High Resolution Radiometer (AVHRR) satellite series provide a data record spanning multiple decades (fig. 5). Spatial computer modeling of the ground and satellite data also allows us to examine the influence that elevation, slope, and terrain aspect have on forest growth, composition, and phenology.

\section{Analysis}

This long record of satellite data can be manipulated to show the relative amount and condi- 


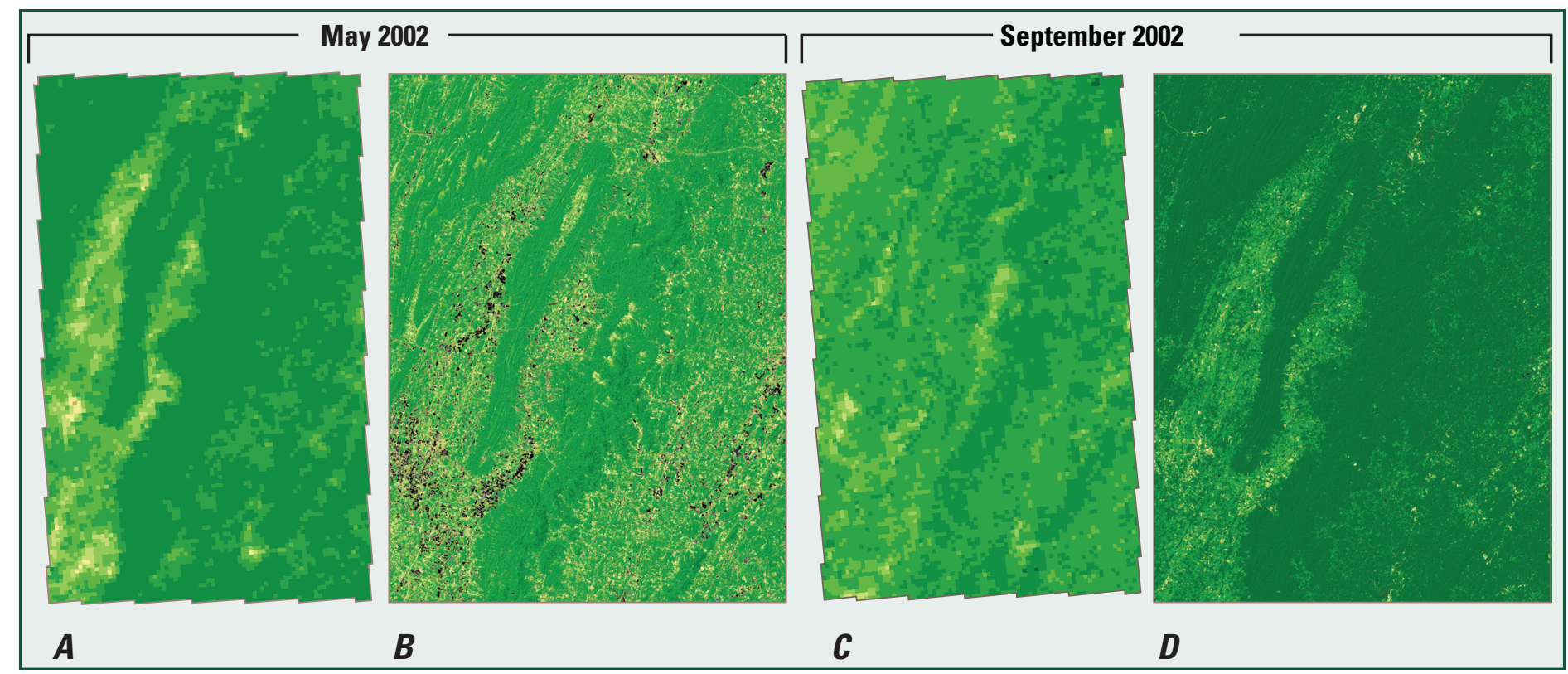

Figure 5. Examples of Advanced Very High Resolution Radiometer (AVHRR) ( $A$ and C) and Landsat Thematic Mapper (TM) (B and D) satellite imagery for the study area in late May and early September 2002. Areas with more abundant and vigorous green vegetation material are shown as dark green, while areas of less green vegetation material are shown in yellow to white colors. Analysis of AVHRR imagery through time provides information on landscape phenology. Landsat data show disturbances and small changes that must be accounted for when calculating phenology.

tion of green vegetation through time. Using records from the park and other types of satellite data analyses, the satellite vegetation-condition database is being processed to identify areas changed by fire, disease, insects, and other disturbances. These areas will be eliminated from further analysis.

The remaining areas are those where changes in phenology most likely would be due to changes in temperature, light, and water availability, all of which are factors affected by changes in climate. Using statistical approaches similar to those applied in stock market analysis (Reed and others, 1994) allows for the derivation of multiple phenologic measurements (fig. 6) for the forested areas that have been relatively unaffected by disturbances over the past several decades. Whether the growing season is starting sooner or lasting longer than in the recent past, as has been observed in some northern latitude forests (Myneni and others, 1997; Zhou and others, 2001), is of particular interest. Climate change may also alter the timing of the peak of the growing season or the total amount of growth in a given season. Trends in these characteristics are being investigated.

\section{You Can Help!}

In collaboration with the National Science Foundation, the U.S. Geological Survey has established the USA National Phenology Network (USA-NPN) to coordinate the collection and analysis of phenologic data on plants and animals from throughout the Nation (Betancourt and others, 2005). Become involved by recording when plants first leaf out and bloom each year. Citizen participation is encouraged. More information on the USA-NPN and the citizen science effort can be found at www.usanpn.org.

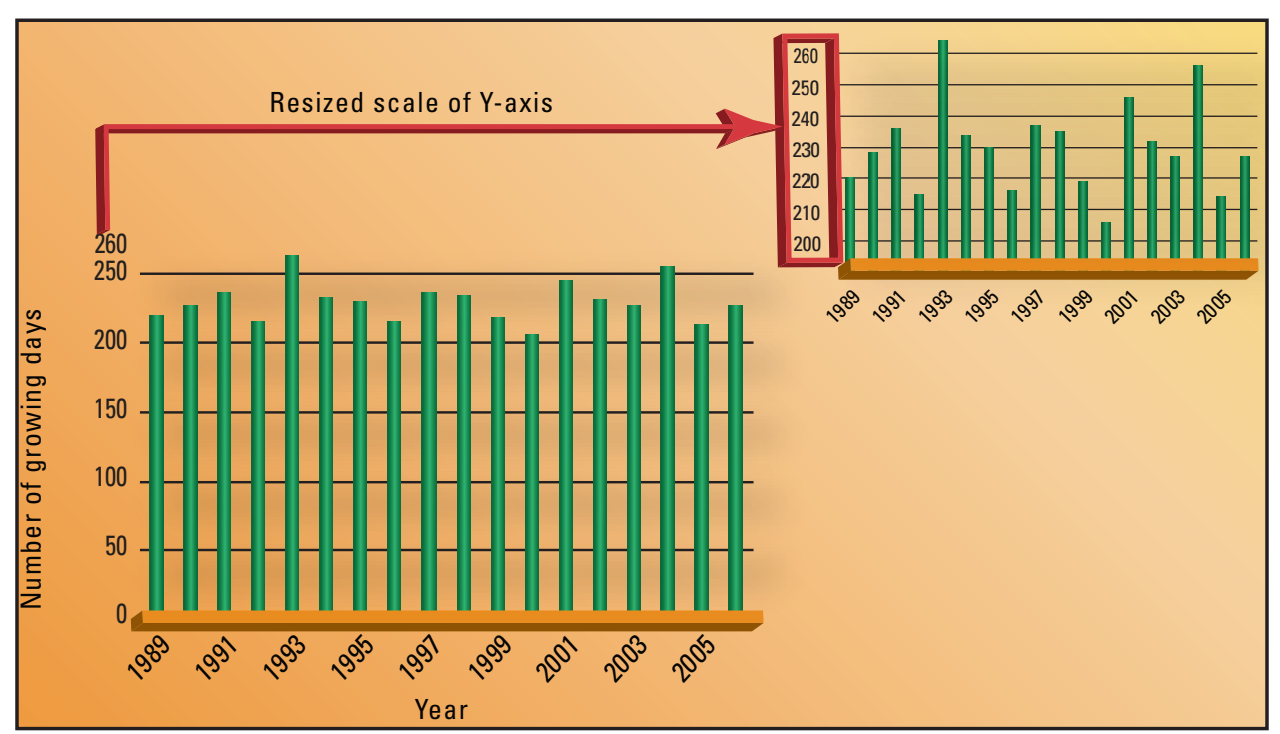
D., Shabanov, N.V., and Myneni, R.B., 2001, Variations in northern vegetation activity inferred from satellite data of vegetation index during 1981 to 1999: Journal of Geophysical Research, v. 106, no. D17, p. 20,069-20,083.

\section{By John W. Jones and Jesse D. Osborne}

\section{For more information, contact:}

John W. Jones

Phone: (703) 648-5543

Fax: (703) 648-4603

E-mail: jwjones@usgs.gov

Figure 6. An example of phenologic metrics derived for a single square kilometer area imaged by the Advanced Very High Resolution Radiometer (AVHRR). 